\title{
Parâmetros agronômicos de gramíneas perenes de clima temperado
}

\author{
Agricultural parameters of perennial winter grasses
}

\section{Ana Lúcia Hanisch ${ }^{1 *}$, Ulisses de Arruda Córdova ${ }^{2}$, Vagner Miranda Portes ${ }^{3}$, Jefferson Araújo Flaresso ${ }^{2}$ e Valdenize Pianaro ${ }^{4}$}

Recebido em 25/11/2015 / Aceito em 01/08/2016

\section{RESUMO}

A introdução de cultivares de forrageiras oriundas de diferentes países pode ser uma opção de transferência de tecnologia a curto prazo para acesso a materiais vegetativos de melhor potencial produtivo. O objetivo deste trabalho foi avaliar cultivares de gramíneas perenes de clima temperado provenientes do Uruguai e Nova Zelândia às condições edafoclimáticas do estado de Santa Catarina, durante os anos de 2010 a 2012. Foram conduzidos, simultaneamente, dois ensaios, em quatro regiões fisiográficas do Estado: Oeste, Meio Oeste, Planalto Sul e Planalto Norte. No ensaio 1 foram avaliados cultivares de Lolium perenne, festulolium e aveia-perene e no ensaio 2 cultivares de Festuca arundinaceae e dáctilo. Houve interação entre cultivares e locais, nos dois ensaios, nos dois anos de avaliação. Azevém-perene e festulolium reduziram significativamente a produção de massa seca (MS) ao longo do período nas regiões Oeste, Meio Oeste e Planalto Norte, sendo recomendado apenas para a região do Planalto Sul. A aveia-perene pode ser indicada para as duas regiões de Planalto, onde perenizou. No ensaio 2, as festucas cv. Epagri 312 (testemunha) e cv. Aurora destacaram-se nos quatro locais, com valores médios de 9 e $7 \mathrm{t} \mathrm{ha}^{-1} \mathrm{de}$ MS, respectivamente, para o primeiro e segundo períodos de avaliação.

PALAVRAS-CHAVE: Lolium perenne, Arrhenatherum elatius, Festuca arundinacea, Dactylis glomerata, festulolium.

\section{ABSTRACT}

Introduction of forage cultivars of different countries can be an option for technology short-term transfer for access to vegetative materials for better production potential. The objective of this study was to evaluate cultivars of temperate climate perennial grasses from Uruguay and New Zealand in soil and climatic conditions in Santa Catarina State, during the years 2010 to 2012. Two simultaneous experiments were conducted, in four physiographic regions of the State: West, Midwest, South Plateau and North Plateau. In trial 1 cultivars of Lolium perenne, festulolium and oats perennial and in trial 2 cultivars of Festuca arundinaceae and dactylis were evaluated. There was interaction between cultivars and localization in both trials, during the two years of evaluation. Perennial ryegrass and festulolium significantly reduced dry matter production (DMP) over the period in the West, Midwest and Northern Plateau and it is recommended only for South Plateau region. Perennial oats may be indicated for the two regions Plateau. In trial 2, the fescue cv. Epagri 312 (control) and cv. Aurora stood out in four locations, with average values of 9 and $7 \mathrm{t} \mathrm{ha}^{-1}$ of dry matter, respectively for the first and second periods of evaluation.

KEYWORDS: Lolium perenne, Arrhenatherum elatius, Festuca arundinacea, Dactylis glomerata, festulolium.

\footnotetext{
${ }^{1}$ Empresa de Pesquisa Agropecuária e Extensão Rural de Santa Catarina, Canoinhas, SC, Brasil.

${ }^{2}$ Empresa de Pesquisa Agropecuária e Extensão Rural de Santa Catarina, Lages, SC, Brasil.

${ }^{3}$ Empresa de Pesquisa Agropecuária e Extensão Rural de Santa Catarina, Chapecó, SC, Brasil.

${ }^{4}$ Empresa de Pesquisa Agropecuária e Extensão Rural de Santa Catarina, Florianópolis, SC, Brasil.

*Autor para correspondência <analucia@epagri.sc.gov.br>
} 


\section{INTRODUÇ̃̃O}

No Brasil, o uso de gramíneas perenes de clima temperado é uma tecnologia pouco difundida, seja em função do reduzido número de espécies e cultivares adaptadas com reconhecida perenização, ou em função da necessidade de aprimorar o manejo com emprego de práticas culturais mais eficientes para essas espécies. Em Santa Catarina, ao longo das últimas décadas ensaios têm sido realizados para avaliação de diferentes espécies (FLARESSO et al. 1997, VIDOR et al. 1997, HANISCH \& GISLON 2010, HANISCH et al. 2011) e os resultados tem confirmado a excelente composição nutricional desses materiais, porém indicam baixa persistência às condições edafoclimáticas da maioria das regiões do estado. Dentre os materiais com resultados promissores, constam a festuca (Festuca arundinacea Schreb) e a aveia-perene (Arrhenatherum elatius), que, até recentemente, apresentavam limitação quanto a disponibilidade de sementes no mercado e poucos cultivares.

A introdução de cultivares de forrageiras melhoradas geneticamente em diferentes países tem sido considerada uma opção de transferência de tecnologia a curto prazo para acesso a materiais vegetativos de melhor potencial produtivo. Essa premissa levou o Estado de Santa Catarina a assinar convênio de cooperação em 2009, para acesso a materiais forrageiros da Nova Zelândia e Uruguai, incluindo gramíneas perenes de clima temperado utilizadas nestes países e com perspectiva de potencial produtivo para o Estado.

Dentre as espécies avaliadas destacam-se o azevém-perene (Lolium perenne L.) que é a forrageira perene mais comumente utilizada em países como a Austrália (LUDEMANN et al. 2015), Nova Zelândia (MINNEE 2011), região Sul do Chile (BALOCCHI \& LÓPEZ 2009), França (DELABY et al. 2001) e Uruguai, em função de sua excelente qualidade nutricional e adaptação produtiva. Nas últimas décadas, em função dos trabalhos de melhoramento genético com o objetivo de aumentar a digestibilidade da forragem, seu uso tem sido intensificado em diferentes países, com consequente aumento da produção animal, atraindo interesse de produtores e técnicos para sua inclusão nos sistemas de produção (BEECHER et al. 2013, LUDEMANN et al. 2015). No Brasil são raros os trabalhos de avaliação com cultivares dessa espécie (LESAMA 2002), sendo avaliada, em geral, em ensaios comparativos com outras espécies de azevéns anuais (OLIVEIRA et al. 2014).

Em relação às espécies perenes de clima temperado já submetidas ao melhoramento genético e introduzidas no Brasil, até recentemente, apenas a festuca era cultivada para a formação de pastagens perenes de inverno por possuir disponibilidade de sementes comerciais (SCHEFFER-BASSO et al. 2002, HANISCH \& GISLON 2010). O potencial de produção de forragem dessa espécie no Sul do Brasil tem variado entre 4 a $7 \mathrm{t} \mathrm{ha}^{-1}$ ano $^{-1}$, respectivamente, para clima Cfa e Cfb (FLARESSO et al. 2001, ROSA et al. 2008, HANISCH \& GISLON 2010), considerados baixos para forrageiras perenes. No entanto, a disponibilidade de novos cultivares no mercado tem suscitado interesse de produtores e técnicos em busca de materiais que atendam aos períodos de vazio forrageiro de outono-inverno, com qualidade e persistência.

A avaliação em rede de novas forrageiras é uma etapa inicial de fundamental importância na indicação técnica de cultivares, uma vez que evita a disseminação de materiais não adaptados à determinadas condições edafoclimáticas. Para espécies perenes essa indicação técnica é ainda mais importante, uma vez que as mesmas permanecem ocupando áreas nas propriedades durante todo o ano.

Este trabalho foi conduzido com o objetivo de avaliar os parâmetros agronômicos de produtividade, crescimento estacional e persistência de gramíneas perenes de clima temperado oriundas do Uruguai e Nova Zelândia a diferentes condições edafoclimáticas de Santa Catarina.

\section{MATERIAL E MÉTODOS}

Foram implantados dois ensaios de validação de cultivo e uso para avaliação de cultivares de gramíneas perenes de clima temperado em quatro Estações Experimentais pertencentes à Empresa de Pesquisa e Extensão Rural de Santa Catarina (Epagri), localizadas nas regiões do Oeste Catarinense, no município de Chapecó $\left(27^{\circ} 05^{\prime} 17,9^{\prime \prime} \mathrm{S}\right.$ e $52^{\circ} 38^{\prime} 11,9^{\prime \prime}$ W, 649 m a.n.m); do Meio Oeste, em Campos Novos $\left(27^{\circ} 22^{\prime} 59,6^{\prime \prime} \mathrm{S}\right.$ e $51^{\circ} 12^{\prime} 55,9^{\prime \prime} \mathrm{W}$ e $920 \mathrm{~m}$ a.n.m.); do Planalto Sul, no município de São Joaquim (2817'39" S e $49^{\circ} 55^{\prime} 56^{\prime \prime} \mathrm{W}$ e $1412 \mathrm{~m}$ a.n.m.) e na região do Planalto Norte Catarinense no município de Papanduva (26 $22^{\prime}$ ' S e $50^{\circ} 16^{\prime}$ W, altitude de 800 
$\mathrm{m}$ a.n.m.). O clima caracteriza-se como Cfa em Chapecó e $\mathrm{Cfb}$ nas demais regiões, de acordo com a classificação de Köppen, sendo considerado $\mathrm{Cfb}$ de altitude no município de São Joaquim. Os dados de média mensal das temperaturas máximas e mínimas e precipitação mensal por local e ano encontram-se na Figura 1. Com relação à incidência de geadas, de acordo com o Centro de Informações de Recursos Ambientais e de Hidrometeorologia de Santa Catarina (Ciram) da Epagri, de setembro de 2010 e fevereiro de 2012 (período de realização dos cortes para avaliação), ocorreram 117 geadas em São Joaquim, 19 em Papanduva, 14 em Campos Novos e 10 em Chapecó.

Em todos os locais os dois ensaios foram conduzidos em delineamento experimental de blocos completos casualizados, com três repetições e seis tratamentos, compostos por diferentes genótipos de gramíneas perenes de clima temperado. A área das parcelas foi formada por oito linhas de cinco metros de comprimento, espaçadas de $0,2 \mathrm{~m}$, sendo consideradas úteis as quatro linhas centrais, eliminando-se $0,5 \mathrm{~m}$ nas extremidades.

No ensaio 1, em Chapecó, Campos Novos e São Joaquim os genótipos avaliados foram: azevém-
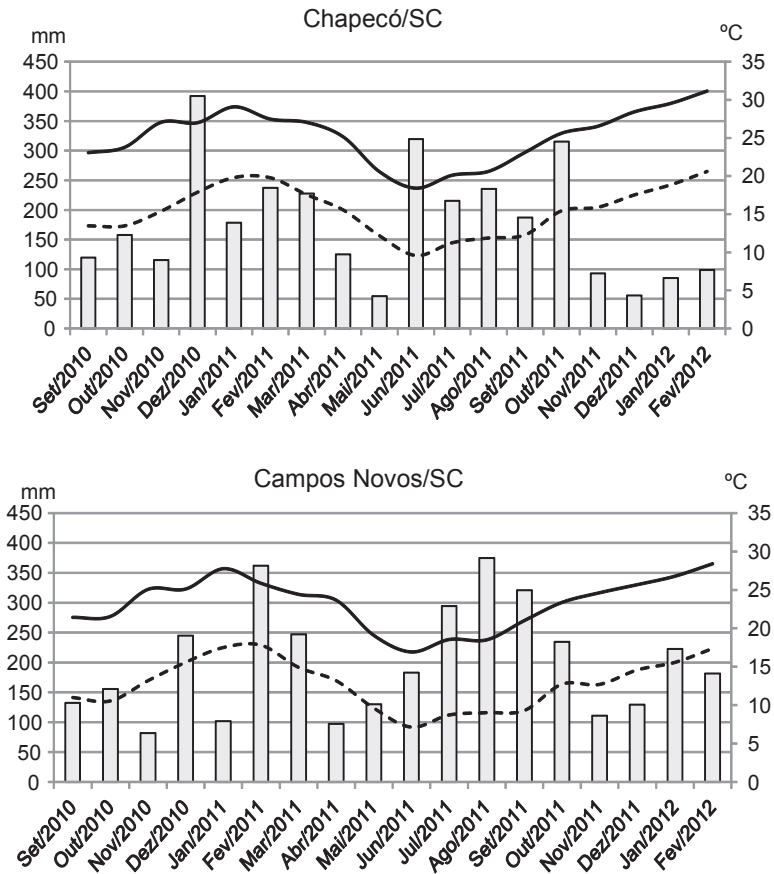

perene (Lolium perenne L.) cultivares Delish, Banquet e Extreme; Festulolium cv. Merlin, aveiaperene (Arrhenatherum elatius L.) cv. Santa Vitória e Festuca arundinaceae Schreb. cv. Epagri 312 - Lages, como testemunha. Em Papanduva, foram avaliados também seis genótipos sendo, no entanto, substituído o Festulolium por Lolium perenne L. cv. Horizon.

No ensaio 2 foram avaliados em todos os locais, cinco cultivares de Festuca arundinaceae Schreb. (Epagri 312 - Lages (testemunha), Quantum II, Aurora, Rizomat e Fortuna) e Dactilys glomerata L. cv. PG 68.

Os solos das áreas experimentais foram classificados como Latossolo Vermelho Distrófico em Chapecó e em Papanduva, Cambissolo Húmico Hálico em São Joaquim e Nitossolo Vermelho em Campos Novos (EMBRAPA 2006). Os solos foram preparados em sistema convencional, com uma aração e duas gradagens, sendo corrigidos os níveis de fertilidade conforme as recomendações de adubação de cada área, de acordo com o Manual de Adubação e de Calagem para SC e RS (CQFS RS/SC 2004). A adubação nitrogenada foi parcelada em função dos cortes, sendo aplicados $20 \mathrm{~kg} \mathrm{ha}^{-1}$ após cada corte para avaliação, durante todo o período de condução
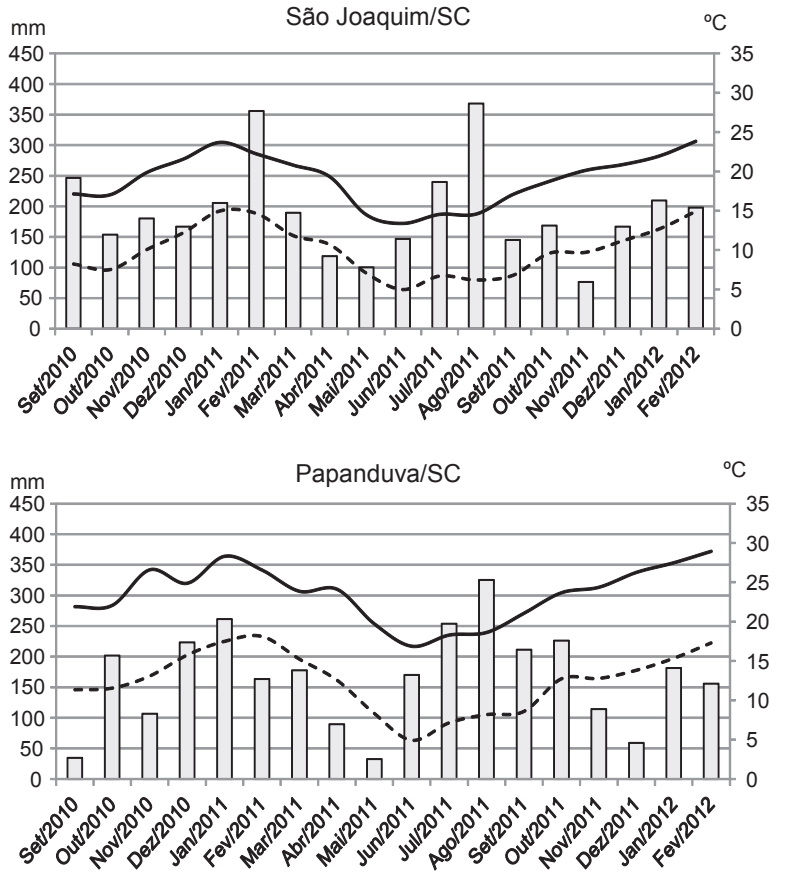

Figura 1 - Médias mensais de precipitação (colunas), temperaturas máximas (linha contínua) e mínimas (linha pontilhada) dos Municípios de Chapecó, São Joaquim, Campos Novos e Papanduva, SC, no período de setembro/2010 a fevereiro/2012.

Figure 1 - Average monthly rainfall (columns), high (solid line) and low temperatures (dotted line) of Chapecó, São Joaquim, Campos Novos and Papanduva, Santa Catarina - Brazil between September/2010 and February/2012. 
dos ensaios.

A semeadura foi realizada manualmente, em linhas, adotando-se a densidade de sementes de $20 \mathrm{~kg}$ $\mathrm{ha}^{-1}$ para as cultivares de azevém-perene, festulolium e festucas e $15 \mathrm{~kg} \mathrm{ha}^{-1}$ para dáctilo. A incorporação ao solo foi realizada a um centímetro de profundidade com auxílio de enxada. As parcelas foram mantidas livres de invasoras através da aplicação de herbicidas seletivos para poáceas, realização de capinas e limpeza manual das parcelas, sempre que necessário.

Para determinação da massa seca de forragem (MSF) foram realizados cortes, sempre que a altura da pastagem atingia entre $20-25 \mathrm{~cm}$, deixando-se resíduo de $5-7 \mathrm{~cm}$ de altura do nível do solo. Os cortes foram realizados sempre que $50 \%$ das parcelas atingiam a altura recomendada. Após cada corte de avaliação, procedeu-se com o corte de uniformização da parcela. As amostras para avaliação foram conduzidas ao laboratório, onde foram pesadas e secas em estufa a $65^{\circ} \mathrm{C}$, com circulação forçada de ar, por 72 horas e pesadas posteriormente, para estimativa do teor de massa seca (MS). A MSF produzida anualmente foi obtida pela somatória de todos os cortes, expressos em quilos por hectare.

No Planalto Norte foi avaliada ainda a persistência das gramíneas, através da análise de cobertura de solo. As amostragens foram realizadas sempre durante a segunda quinzena do mês de setembro nos anos de 2010 a 2012, sendo que a primeira avaliação ocorreu seis meses após a semeadura do experimento. Para isso, foram realizadas fotos digitais das parcelas, na altura de $1,30 \mathrm{~m}$ do solo com a câmara em posição horizontal. As fotos foram analisadas digitalmente através do processo de grid fotográfico, sendo os valores apresentados em percentuais de cobertura do solo (VARELLA et al. 2002). Para análise de variância os valores foram transformados utilizando-se a expressão $\sqrt{ } \mathrm{x}+1$.

Para cada ensaio, os dados de todos os locais e anos, foram submetidos à análise de normalidade pelo teste de Shapiro-Wilk e variância pelo teste F utilizando-se os programas R e Sisvar. Quando constatados efeitos significativos dos tratamentos, as médias foram comparadas pelo teste de Scott-Knott a $5 \%$ de probabilidade. Foi realizada análise conjunta dos quatro locais, por ano de avaliação, considerandose como fatores os tratamentos, os locais e suas interações para a MSF, utilizando-se também o teste de Scott-Knott a 5\% de probabilidade para comparação de médias. No ensaio 1, os tratamentos Festulolium cv. Merlin e Lolium perenne L. cv. Horizon foram excluídos da análise conjunta, sendo apresentados apenas nos locais onde constavam dos ensaios.

Os resultados da análise de cobertura do solo realizados no Planalto Norte foram analisados em parcelas subdivididas, alocando-se os tratamentos nas parcelas e os anos nas subparcelas. Quando constatados significância, as médias foram comparadas pelo teste de Scott-Knott, também a 5\% de probabilidade.

\section{RESULTADOS E DISCUSSÃO}

No Ensaio 1 houve interação entre tratamentos e locais nos dois anos de avaliação para MSF, indicando grande variação entre os materiais (Tabela 1). A testemunha festuca cv. Epagri 312 - Lages foi um dos materiais mais produtivo em todas as regiões do Estado no primeiro período de avaliação, indicando que não houve contribuição significativa neste indicador, por parte dos materiais introduzidos. A aveia-perene destacou-se, juntamente com a testemunha, nas regiões do Planalto Sul, Planalto Norte e Meio-Oeste, indicando potencial de adaptação.

No primeiro período de avaliação os cultivares de azevém-perene não diferiram entre si nas duas regiões de Planalto, com MSF acima de $8 \mathrm{t} \mathrm{ha}^{-1}$. Nas regiões Oeste e Meio Oeste o cv. Delish foi o mais produtivo, mas os valores observados nestas regiões, de 6,4 e 5,2 t ha $^{-1}$ ano $^{-1}$, são valores baixos de MSF para forrageiras perenes e foram semelhantes ao obtido por LESAMA (2002) na avaliação de azevém-perene sob pastejo, em clima Cfb no Paraná, cuja produção variou de 5,1 a 6,3 tha ${ }^{-1}$ de MS. O desempenho apresentado pelos cultivares de azevém-perene nas regiões de Planalto, indicam melhor adaptação a essa condição ambiental.

Em experimentos que objetivam a seleção de materiais perenes a realização de avaliações periódicas de cultivares ao longo do tempo, torna-se indispensável para orientar os trabalhos de seleção de cultivares de plantas forrageiras. Neste sentido, o segundo período de avaliação (março/2011 a fevereiro/2012) teve importância significativa para caracterizar a perenização dos cultivares.

No Planalto Sul, no segundo período de avaliação (2011/2012), aveia-perene e festuca apresentaram MSF próxima a $10 \mathrm{tha}^{-1}$, não diferindo entre si (Tabela 1). Embora não tenha sido realizado análise comparativa entre os anos, é possível verificar que essas duas espécies mantiveram valores muito 
Tabela 1 - Massa seca de forragem ( $\mathrm{kg} \mathrm{ha}^{-1}$ de MS) de cultivares de azevém-perene, festulolium, aveia perene e festuca, durante dois períodos de crescimento (2010/2011 e 2011/2012), em quatro regiões fisiográficas de Santa Catarina.

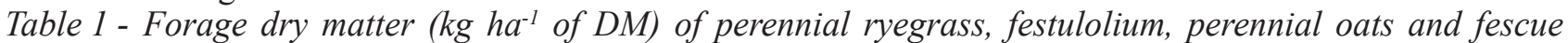
cultivars, for two growth periods (2010/2011 and 2011/2012), in four physiographic regions of Santa Catarina, Brazil.

\begin{tabular}{|c|c|c|c|c|}
\hline Tratamentos & Oeste & Meio Oeste & Planalto Sul & $\begin{array}{c}\text { Planalto } \\
\text { Norte }\end{array}$ \\
\hline & \multicolumn{4}{|c|}{$2010 / 2011$} \\
\hline L. perenne L. cv. Delish & 6400 b B & $5200 \mathrm{~b} \mathrm{C}$ & 8486 b A & 8560 a $\mathrm{A}$ \\
\hline L. perenne L. cv. Banquet & 5445 c B & 3700 c C & $8700 \mathrm{~b} A$ & 7713 a $\mathrm{A}$ \\
\hline L. perenne L. cv. Extreme & 5530 c B & 3923 c C & 8336 b A & 7443 a A \\
\hline Festulolium cv. Merlim & $7082 \mathrm{~b}$ & $4570 \mathrm{~b}$ & $5760 \mathrm{c}$ & - \\
\hline L. perenne L. cv. Horizon & - & - & - & $8521 \mathrm{a}$ \\
\hline Arrhenatherum elatius L. cv. S. Vitória & $6250 \mathrm{~b} \mathrm{~B}$ & 8770 a $\mathrm{A}$ & 9417 b A & 8521 a $\mathrm{A}$ \\
\hline Festuca arundinacea Schreb. cv. Epagri 312 (T) & 8786 a B & 7902 a B & 11121 a A & 8183 a B \\
\hline \multirow[t]{2}{*}{$\mathrm{CV} \%$} & 9,40 & & & \\
\hline & \multicolumn{4}{|c|}{$2011 / 2012$} \\
\hline L. perenne L. cv. Delish & 6176 a A & 3231 c B & $5821 \mathrm{~b} \mathrm{~A}$ & $5300 \mathrm{~b} \mathrm{~A}$ \\
\hline L. perenne L. cv. Banquet & $4813 \mathrm{~b}$ B & 3592 c B & $6468 \mathrm{~b} \mathrm{~A}$ & $5530 \mathrm{~b} \mathrm{~A}$ \\
\hline L. perenne L. cv. Extreme & $4247 \mathrm{~b} C$ & 3280 c C & $6720 \mathrm{~b} \mathrm{~A}$ & $5222 \mathrm{~b} \mathrm{~B}$ \\
\hline Festulolium cv. Merlim & $6305 \mathrm{a}$ & $4730 \mathrm{c}$ & 9203 a & - \\
\hline L. perenne L. cv. Horizon & - & - & - & $6604 \mathrm{~b}$ \\
\hline Arrhenatherum elatius L. cv. S. Vitória & $4313 \mathrm{~b} \mathrm{D}$ & $6367 \mathrm{~b} \mathrm{C}$ & 9627 a A & 7981 a B \\
\hline Festuca arundinacea Schreb. cv. Epagri 312 (T) & 5477 a C & 7810 a B & 10606 a A & $6170 \mathrm{~b} \mathrm{C}$ \\
\hline $\mathrm{CV} \%$ & 13,54 & & & \\
\hline
\end{tabular}

Médias seguidas de letras iguais, minúsculas nas colunas e maiúsculas nas linhas, não diferem entre si pelo teste de ScottKnott a 5\% de probabilidade. $\mathrm{CV}=$ coeficiente de variação.

próximas entre os dois períodos, e as mais altas do Estado, o que indica adaptação àquela condição.

No segundo período a aveia-perene apresentou valores de MSF próximo a $8 \mathrm{t} \mathrm{ha}^{-1}$ no Planalto Norte, sendo o material mais produtivo do período naquela região. Na região do Meio Oeste o destaque foi a festuca, sendo que manteve valor de MSF praticamente estável entre os anos. Estes resultados indicam a possibilidade de cultivo dessas forrageiras perenes de clima temperado em Santa Catarina apenas para as regiões de clima $\mathrm{Cfb}$, uma vez que na região Oeste, ambas as espécies produziram menos de 5,5 $\mathrm{t} \mathrm{ha}^{-1}$ no segundo período (Tabela 1).

$\mathrm{Na}$ região Oeste, nenhum material superou 6,3 t ha $^{-1}$ no segundo ano. Produtividades aproximadas são, comumente, obtidas por espécies anuais de inverno como azevém-anual (FLORES et al. 2008) e aveia (FERRAZZA et al. 2013), na região Sul do Brasil, apenas durante o período de inverno- primavera sem a ocupação da área durante todo o ano, como ocorre com as pastagens perenes. Dessa forma, não se justifica o cultivo dessas espécies em clima $\mathrm{Cfa}$, onde em função das temperaturas mais elevadas o desempenho de pastagens perenes de verão, facilmente superam valores de MSF acima de $12 \mathrm{t} \mathrm{ha}^{-1}$ (ALMEIDA \& FLARESSO 1991, MIRANDA et al. 2012, JOCHIMS et al. 2015).

Entre os cultivares de azevém-perene, no segundo ano não foram observadas MSF acima de 7 tha $^{-1}$ em nenhuma das quatro regiões. Considerandose o uso de adubação nitrogenada acima de $160 \mathrm{~kg} \mathrm{ha}^{-1}$ ano $^{-1}$, as produtividades observadas para o azevém-perene são baixas para uma espécie perene. Os resultados observados para azevém-perene no Ensaio 1 ficaram muito aquém de resultados relatados nas condições da Nova Zelândia, onde foram obtidos $16,9 \mathrm{t} \mathrm{ha}^{-1}$ de MS para o cv. Banquet, na média de 3 anos em área sob pastejo, sob irrigação (MINNEE 
2011). Neste trabalho, em função de que os cultivares de azevém-perene são provenientes de programas de melhoramento de países que o utilizam em sistemas de produção, esperava-se um desempenho maior que aqueles já obtidos em condições experimentais (FLARESSO et al. 1997, HANISCH \& GISLON 2010), o que não ocorreu.

Dessa forma, embora seja tecnicamente questionável a recomendação de forrageiras perenes com MSF de $6 \mathrm{t} \mathrm{ha}^{-1}$ ano $^{-1}$, para a região do Planalto Sul, em função das adversidades naturais impostas pelas temperaturas muito baixas, o uso de cultivares de azevém-perene pode ser uma alternativa promissora para a região. Nesta região são poucas as opções forrageiras com MSF anual acima de $6 \mathrm{tha}^{-1}$. HANISCH et al. (2011) avaliando acessos de capimlanudo (Holcus lanatus L.) como opção forrageira para a região, obtiveram MSF de $7 \mathrm{t} \mathrm{ha}^{-1}$ ano $^{-1}$ apenas para o acesso Urubici, sendo que as demais ficaram abaixo $5 \mathrm{t} \mathrm{ha}^{-1}$ de MS. ROSA et al. (2008) conduzindo diversos ensaios com forrageiras de clima temperado, obtiveram valores de MSF em torno de $6 \mathrm{t} \mathrm{ha}^{-1} \mathrm{ano}^{-1}$ para todos os cultivares na região de São Joaquim.

Para as demais regiões do Estado, não é recomendável o uso da espécie Lolium perenne em função da reduzida MSF anual e baixa persistência, visto que, é possível manter as áreas ocupadas com espécies perenes de verão como Axonopus catharinensis, Hemarthria altissima cv. Flórida, Cynodon sp. entre outras, que alcançam, facilmente, valores de MSF acima $12 \mathrm{t} \mathrm{ha}^{-1}$ ano $^{-1}$ (ALMEIDA \& FLARESSO 1991, SOARES et al. 2009, HANISCH et al. 2012, MIRANDA et al. 2012, JOCHIMS et al. 2015) e podem ser sobressemeadas durante o inverno com forrageiras anuais de clima temperado, otimizando de forma mais eficiente o uso da área para produção animal.

Na Tabela 2 estão apresentados os dados do percentual de cobertura de solo do Ensaio 1 na região do Planalto Norte. Não houve diferença entre os cultivares de azevém-perene ao longo do tempo. Os resultados confirmam a baixa adaptação da espécie Lolium perenne às condições da região e justificam a redução observada na MSF, uma vez que no segundo ano o percentual de cobertura do solo pelas plantas reduziu em torno de $30 \%$, e no terceiro ano a redução foi de $50 \%$ em relação ao primeiro ano (Tabela 2). Por outro lado, Arrhenatherum elatius cv. Santa Vitória e Festuca arundinaceae cv. Epagri 312 - Lages manteve estável a porcentagem de cobertura do solo ao longo do tempo, indicando adaptação às condições edafoclimáticas e ao manejo adotado.

Na Figura 2 estão apresentados os dados da dinâmica de produção das gramíneas perenes do Ensaio 1, durante todo o período de avaliação. Apesar das datas de corte não terem sido as mesmas em todas as regiões, foi realizado uma aproximação entre as mesmas para as quatro regiões com a finalidade de permitir a comparação entre elas.

Tabela 2 - Percentual de cobertura do solo por gramíneas perenes de clima temperado na região do Planalto Norte Catarinense, ao longo de três anos.

Table 2 - Ground cover percentage of perennial grasses in temperate climate in the North Plateau of Santa Catarina, during three years.

\begin{tabular}{lccc}
\hline & Set/2010 & Set/2011 & Set/2012 \\
\hline L. perenne L. cv. Delish & 100 a A & 58 b B & 47 b B \\
L. perenne L. cv. Banquet & 100 a A & 69 b B & 59 b B \\
L. perenne L. cv. Extreme & 100 a A & 62 b B & 50 b B \\
L. perenne L. cv. Horizon & 97 a A & 67 b B & 66 b B \\
Arrhenatherum elatius L. cv. Santa Vitória & 93 a A & 85 a B & 92 a A \\
Festuca arundinacea Schreb. cv. Epagri 312 - Lages & 81 a A & 81 a A & 90 a A \\
\hline CV 1 (\%) & 16,61 & & \\
CV 2 (\%) & 21,59 & & \\
\hline
\end{tabular}

Médias seguidas de mesma letra, minúscula na coluna e maiúscula na linha, não diferem entre si pelo teste de ScottKnott a 5\% probabilidade. CV = coeficiente de variação; CV 1 = erro da parcela; CV 2 = erro geral. 

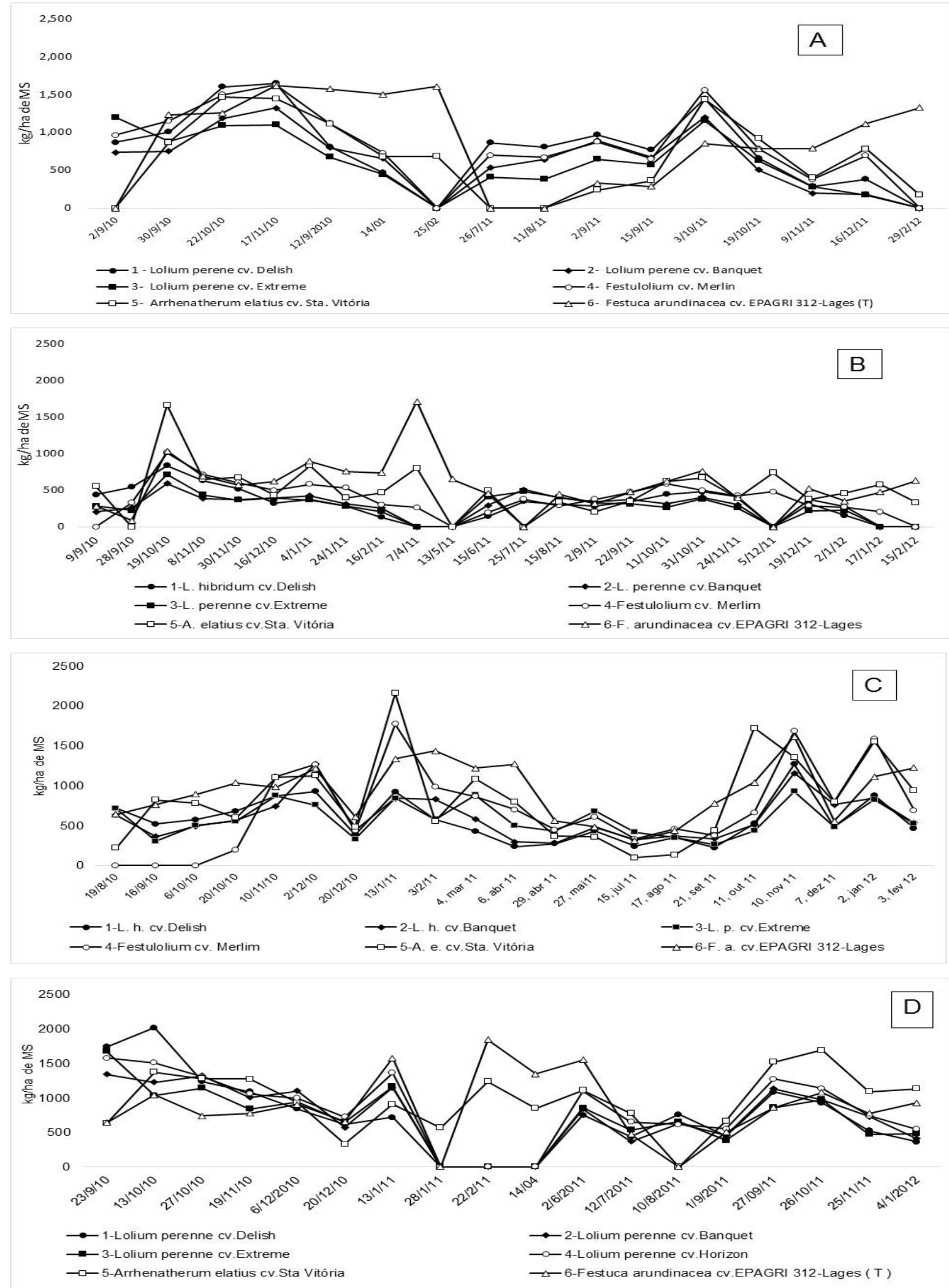

Figura 2 - Dinâmica da produção ao longo do período de set/2010 a fev/2012 para o Ensaio 1 em Chapecó (A), Campos Novos (B), São Joaquim (C) e Canoinhas (D), SC.

Figure 2 - Production dynamics between Sep/ 2010 and Feb/2012, for Assay 1, in Chapecó (A), Campos Novos (B), São Joaquim (C) and Canoinhas (D), Santa Catarina, Brazil. 
É possível verificar as diferenças regionais em relação à dinâmica de produção das forrageiras avaliadas.

Considerando-se as produções obtidas ao longo dos anos na região Oeste (Figura 2A), verificou-se comportamento primaveril para as gramíneas nesta região, com um decréscimo gradual na MSF de outubro a fevereiro no primeiro período de avaliação, que foi mais acentuado no segundo período. Nos meses de verão os cultivares de azevém-perene cessaram seu crescimento na região, retomando apenas no mês de julho quando ocorrem temperaturas mais amenas para aquela região (Figura 1). $\mathrm{O}$ aumento na temperatura provoca severas reduções na produção de genótipos de azevém-perenes como observado na Europa (APER et al. 2014). A festuca apresentou comportamento estival, com MSF acima de $1500 \mathrm{~kg}$ ha $^{-1}$ corte $^{-1}$ nos meses de janeiro e fevereiro nos dois períodos de avaliação, e produções abaixo de $1000 \mathrm{~kg}$ $\mathrm{ha}^{-1}$ de MS nos cortes de inverno e primavera.

No Meio Oeste (Figura 2B), a dinâmica da produção confirma a baixa adaptação das espécies avaliadas para essa região, em função da baixa produtividade por corte, com valores de MSF entre 500 e $1000 \mathrm{~kg} \mathrm{ha}^{-1}$ na maioria das avaliações. A baixa resposta dos materiais às condições do Meio Oeste pode estar relacionada à sua localização em área de transição entre clima $\mathrm{Cfa}$ e $\mathrm{Cfb}$, o que tende a maior ocorrência de variações climáticas, que podem ter afetado a fisiologia das plantas, em especial o perfilhamento, uma vez que os cortes foram realizados em função da altura das plantas, o que indica que as parcelas nesta região apresentavam densidade menor.

Nas duas regiões de Planalto (Figuras 2C e 2D) apesar da MSF total dos cultivares de azevém-perene terem sido semelhante entre ambas, a dinâmica da produção foi diferente. No Planalto Norte ocorreu redução gradual da produção entre a primavera e o verão, ocorrendo um corte ainda no mês de janeiro de 2011 para todos os cultivares de azevém-perene, que em seguida, cessaram seu crescimento. Por outro lado, no Planalto Sul (Figura 2C), os cultivares apresentaram comportamento estival, estendendo o período de crescimento até os meses de abril. Festulolium, aveiaperene e festuca alcançaram MSF acima de $1500 \mathrm{~kg}$ $\mathrm{ha}^{-1}$ por corte a partir do mês de novembro, período no qual as temperaturas tendem a subir nesta região, mas dificilmente ultrapassam $25{ }^{\circ} \mathrm{C}$ (Figura 1). Espécies de clima temperado apresentam um crescimento ótimo aos $18,3{ }^{\circ} \mathrm{C}$, sendo que dos $15,6^{\circ} \mathrm{C}$ aos $21,1^{\circ} \mathrm{C}$, produz cerca de $95 \%$ da taxa máxima de crescimento, reduzindo seu crescimento em temperaturas acima e abaixo desses valores (WEIHING 1963), o que justifica a maior adaptação das espécies avaliadas à região do Planalto Sul Catarinense.

Em experimentos de avaliação de cultivares de forrageiras perenes a MSF total é uma informação fundamental que permite comparação com outras espécies perenes, mas não demonstram o comportamento ao longo do ano e, isoladamente, não fornecem informações necessárias para a tomada de decisões (FERRAZZA et al. 2013). Dessa forma, a distribuição da produção de forragem no tempo, é a que define a magnitude dos vazios forrageiros e auxilia na tomada de decisão acerca do planejamento forrageiro.

No Ensaio 2, de festucas, de modo semelhante ao observado no Ensaio 1, foi verificado interação entre forrageiras e regiões para a MSF, nos dois períodos de avaliação (Tabela 3). Entre os cultivares de festuca, no primeiro ano de avalição, os valores de MSF variaram de 2,3 a 11,8 $\mathrm{t} \mathrm{ha}^{-1}$ revelando grande variação entre os mesmos.

No primeiro ano, os cultivares que se destacaram em todas as regiões foram as festucas cv. Epagri 312 - Lages (testemunha) e o cv. Aurora, sendo que este obteve a maior MSF de todo o Estado, na região do Planalto Sul. Os maiores valores para MSF para todos os cultivares, à exceção da festuca cv. Fortuna, foram observados naquela região (Tabela 3 ). $\mathrm{O}$ cv. Fortuna apresentou maior adaptação às temperaturas mais altas de clima Cfa, sendo que esteve entre os materiais mais produtivos na região Oeste. Na região do Planalto Norte os valores para MSF foram mais baixos que nas outras regiões (à exceção da festuca cv. Fortuna), sendo que apenas os cultivares Epagri 312 - Lages e Aurora ultrapassaram $7 \mathrm{t} \mathrm{ha}^{-1}$ de MS.

No segundo período de avaliação (2011-2012) na região Oeste não foram observados valores de MSF anual acima de 7,2 $\mathrm{t} \mathrm{ha}^{-1}$ (Tabela 3), que são considerados valores muito baixos para forrageiras perenes nesta região, conforme já justificado em relação ao Ensaio 1, uma vez que a mesma área poderia ser ocupada com forrageiras perenes de verão, que alcançam produtividades superiores a $12 \mathrm{t} \mathrm{ha}^{-1}$ ano $^{-1}$ durante seu ciclo de crescimento e permitem a sobressemeadura com forrageiras anuais de inverno, potencializando o uso da área a maior parte do ano (ALMEIDA \& FLARESSO 1991, MIRANDA et al. 2012, JOCHIMS et al. 2015). 
Tabela 3 - Massa seca de forragem $\left(\mathrm{kg} \mathrm{ha}^{-1}\right.$ de MS) durante dois períodos de crescimento (2010/2011 e 2011/2012) de cultivares de festuca e dáctilos em quatro regiões fisiogeográficas de Santa Catarina.

Table 3 - Forage dry matter ( $\mathrm{kg} \mathrm{ha}^{-1}$ of DM) of fescue and dactilys cultivars, for two growth periods (2010/2011 and 2011/2012), in four physiographic regions of Santa Catarina, Brazil.

\begin{tabular}{|c|c|c|c|c|}
\hline Tratamentos & Oeste & Meio Oeste & Planalto Sul & $\begin{array}{c}\text { Planalto } \\
\text { Norte }\end{array}$ \\
\hline & \multicolumn{4}{|c|}{$2010 / 2011$} \\
\hline Festuca arundinaceae cv. Epagri 312 - Lages & 9581 a $\mathrm{A}$ & 9024 a A & $10487 \mathrm{~b} \mathrm{~A}$ & 7413 a B \\
\hline Festuca arundinaceae cv. Quantum II & 9523 a A & $7108 \mathrm{~b}$ B & $9337 \mathrm{~b} \mathrm{~A}$ & 6385 a B \\
\hline Festuca arundinaceae cv. Aurora & 10133 a B & 9078 a C & 11844 a A & 7190 a D \\
\hline Festuca arundinaceae cv. Rizomat & 7484 b B & $7671 \mathrm{~b} \mathrm{~B}$ & 9613 b A & 5661 a $\mathrm{C}$ \\
\hline Festuca arundinaceae cv. Fortuna & 8624 a A & 2342 c D & 4133 c C & 6476 a B \\
\hline Dactilys glomerata L. cv. PG 68 & 5872 с C & 8390 a B & $9840 \mathrm{~b} A$ & 6303 a C \\
\hline \multirow[t]{2}{*}{$\mathrm{CV} \%$} & 9,22 & & & \\
\hline & \multicolumn{4}{|c|}{$2011 / 2012$} \\
\hline Festuca arundinaceae cv. Epagri 312 - Lages & 7184 a B & 5944 a B & 9293 a A & 8002 a A \\
\hline Festuca arundinaceae cv. Quantum II & 6628 a A & 5115 a A & $5740 \mathrm{~d} A$ & 5090 c A \\
\hline Festuca arundinaceae cv. Aurora & 7292 a B & 6667 a B & 10061 a A & $6678 \mathrm{~b} \mathrm{~B}$ \\
\hline Festuca arundinaceae cv. Rizomat & 5800 a B & 5080 a B & 7735 c A & 5303 c B \\
\hline Festuca arundinaceae cv. Fortuna & 6693 a B & 6048 a B & $8380 \mathrm{~b} \mathrm{~A}$ & 6548 b B \\
\hline Dactilys glomerata L. cv. PG 68 & 5890 a B & 5803 a B & 10027 a A & 5891 c B \\
\hline
\end{tabular}

Médias seguidas de letras iguais, minúsculas nas colunas e maiúsculas nas linhas, não diferem entre si pelo teste de ScottKnott a 5\% de probabilidade. $\mathrm{CV}=$ coeficiente de variação.

Nas regiões Meio Oeste e Planalto Norte, no segundo período todos os materiais apresentaram produção de MSF abaixo de 6,7 $\mathrm{t} \mathrm{ha}^{-1}$, à exceção da festuca cv. Epagri 312 - Lages, no Planalto Norte com MSF acima de $8 \mathrm{t} \mathrm{ha}^{-1}$ (Tabela 3). Embora, no Ensaio 1 a festuca e a aveia-perene tenham sido os materiais mais promissores para a região do Planalto Norte, quando comparados com cultivares de azevém-perene, os valores observados no Ensaio 2 são baixos para uma gramínea perene, considerandose a concentração da produção durante a primavera (Figura 2D), aliado ao fato de ocupar o solo durante todo o ano.

À exceção do cv. Quantum II, os demais cultivares de festuca apresentaram excelente adaptação às condições do Planalto Sul Catarinense, sendo que Epagri 312 - Lages e Aurora apresentaram valores de MSF próximos a $10 \mathrm{t} \mathrm{ha}^{-1}$ no segundo ano, praticamente os mesmos valores do primeiro período de avaliação. $\mathrm{O}$ cv. Fortuna apresentou recuperação considerável da MSF nas regiões Meio Oeste e Planalto Sul, indicando estabelecimento lento à essas regiões, mas com potencial de uso a partir do segundo ano. Correlacionando os resultados observados no Ensaio 2, com as limitações naturais da região do Planalto Sul, devido às baixas temperaturas durante um longo período do ano, a festuca apresenta-se como uma alternativa viável de uso para a aquela região, com destaque para os cultivares Aurora e Epagri 312Lages.

De um modo geral, os valores médios nos dois anos observados no Estado para os cultivares de festuca foram superiores aos observados por outros autores em condições semelhantes (FLARESSO et al. 2001, ROSA et al. 2008, HANISCH \& GISLON 2010).

Dactylis glomerata cv. PG 68 apresentou MSF próximo a 10 tha $^{-1}$ de MS no Planalto Sul nos dois anos (Tabela 3 ), estando entre os materiais mais produtivos naquela região no segundo ano, demonstrando a adaptação dessa espécie às condições de altitude. Nas demais regiões do Estado, o dáctilo reduziu a MSF no segundo ano, alcançando em média 5,8 $\mathrm{t} \mathrm{ha}^{-1}$ de MS, que de forma semelhante ao observado nas espécies do Ensaio 1, não demostram potencial para produção nestes locais. 


\section{CONCLUSÃO}

Azevém-perene e festulolium são recomendadas para a região do Planalto Sul, com boa adaptação à clima Cfb de altitudes superiores a 1000 m, porém, não apresenta persistência produtiva para as demais regiões de Santa Catarina. A aveia-perene é indicada para as duas regiões de Planalto, onde perenizou. As festucas apresentam boa adaptação às regiões avaliadas, recomendando-se os cultivares Epagri-312 Lages e Aurora, por apresentarem maior produtividade e persistência da produção.

\section{REFERÊNCIAS}

ALMEIDA EX de \& FLARESSO JA. 1991. Introdução e avaliação de forrageiras tropicais no Alto Vale do Itajaí, Santa Catarina, Brasil. Pasturas Tropicales 13:23-30.

APER J et al. 2014. Drought effect on yield of perennial ryegrass (Lolium perenne L.). In: Quantitative Traits Breeding for Multifunctional Grasslands and Turf. Springer Netherlands: Springer. p.367-371.

BALOCCHI OA \& LÓPEZ IF. 2009. Herbage production, nutritive value and grazing preference of diploid and tetraploid perennial ryegrass cultivars (Lolium perenne L.). Chilean Journal of Agricultural Research 69:331-339.

BEECHER $M$ et al. 2013. The variation in morphology of perennial ryegrass cultivars throughout the grazing season and effects on organic matter digestibility. Grass and Forage Science 70:19-29.

CQFS - RS/SC. COMISSÃO DE QUÍMICA E FERTILIDADE DO SOLO - RS/SC. 2004. Manual de adubação e calagem para os Estados do Rio Grande do Sul e Santa Catarina. 10.ed. Porto Alegre, RS: SBCS/Núcleo Regional Sul; Comissão de Química e Fertilidade do Solo - RS/SC. 394p.

DELABY L et al. 2001. Effect of the level of concentrate supplementation, herbage allowance and milk yield at turnout on the performance of dairy cows in mid lactation at grazing. Animal Science 73:171-181.

EMBRAPA. Centro Nacional de Pesquisa de Solos. 2006. Sistema Brasileiro de Classificação de Solos. 2.ed. Brasília: EMBRAPA. 306p.

EPAGRI/CIRAM. 2015. Monitoramento e Difusão de dados agrometeorológicos em apoio à fruticultura do Planalto Norte Catarinense. Disponível em: http://www. ciram.com.br/MDA_Fruplanorte. Acesso em: 13 abr. 2015. FERRAZZA JM et al. 2013. Dinâmica de produção de forragem de gramíneas anuais de inverno em diferentes épocas de semeadura. Ciência Rural 43:1174-1181.

FLARESSO JA et al. 1997. Introdução e avaliação de gramíneas de inverno no Alto Vale do Itajaí, Santa Catarina. Revista Brasileira de Zootecnia 26:875-880.

FLARESSO JA et al. 2001. Introdução e avaliação de gramíneas perenes de verão no Alto Vale do Itajaí, Santa Catarina. Pesquisa Agropecuária Gaúcha 7:77-86.

FLORES RA et al. 2008. Produção de forragem de populações de azevém anual no estado do Rio Grande do Sul. Revista Brasileira de Zootecnia 37:1168-1175.

HANISCH AL et al. 2011. Comportamento produtivo de populações de capim-lanudo em Santa Catarina. Agropecuária Catarinense 24:64-68.

HANISCH AL et al. 2012. Avaliação agronômica de seis forrageiras perenes subtropicais no Planalto Norte Catarinense. Agropecuária Catarinense 25:57-60.

HANISCH AL \& GISLON I. 2010. Massa de forragem e valor nutritivo de gramíneas perenes de inverno no planalto norte catarinense. Scientia Agraria 11:25-32.

JOCHIMS $F$ et al. 2015. Produtividade de grama missioneira-gigante, amendoim-forrageiro e suas consorciações. Agropecuária Catarinense 28:84-88.

LESAMA MF. 2002. Características estruturais de cultivares de azevém-perene como critério de seleção para maximizar o consumo de vacas leiteiras em pastejo. Tese (Doutorado em Produção Vegetal), Curitiba: UFPR. 78p.

LUDEMANN CI et al. 2015. Higher energy concentration traits in perennial ryegrass (Lolium perenne L.) may increase profitability and improve energy conversion on dairy farms. Agricultural Systems 137:89-100.

MINNEE EMK. 2011. An evaluation of tall fescue (Lolium arundinaceum) as an alternative to perennial ryegrass (Lolium perenne) for use on dairy farms in the Waikato. Tese (Doutorado), University of Waikato. 138p.

MIRANDA $M$ et al. 2012. Dry matter production and nitrogen use efficiency of giant missionary grass in response to pig slurry application. Revista Brasileira de Zootecnia 41:537-543.

OLIVEIRA LV et al. 2014. Características produtivas e morfofisiológicas de cultivares de azevém. Pesquisa Agropecuária Tropical 44:191-197.

ROSA JL et al. 2008. Forrageiras de clima temperado para o Estado de Santa Catarina. Florianópolis: Epagri. 64p.

SCHEFFER-BASSO SM et al. 2002. Comportamento de leguminosas (Adesmia, Lotus, Trifolium) em mistura com festuca. Revista Brasileira de Zootecnia 31:2197-2203.

SOARES AB et al. 2009. Influência da luminosidade no comportamento de onze espécies forrageiras perenes de verão. Revista Brasileira de Zootecnia 38:443-451.

VARELLA CAA et al. 2002. Determinação da cobertura do solo por análise de imagens e redes neurais. Revista Brasileira de Engenharia Agrícola e Ambiental 6:225-229. VIDOR MA et al. 1997. Principais forrageiras para o Planalto de Santa Catarina. Florianópolis: Epagri. 91p. WEIHING RM. 1963. Growth of ryegrass as influenced by temperature and solar radiation. Agronomy Journal 55:519521. 